\title{
Down-regulated expression of Tim-3 promotes invasion and metastasis of colorectal cancer cells
}

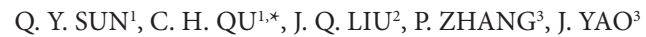

${ }^{1}$ Department of Medical Imaging, Linyi People's Hospital, Linyi 276003, P.R. China; ${ }^{2}$ Department of Paediatrics, Zoucheng People's Hospital, Jining 273500, P.R. China; ${ }^{3}$ Department of Integrated TCM \& Western Medicine, First Affiliated Hospital of Harbin Medical University, Harbin 150001, P.R. China.

${ }^{*}$ Correspondence: qchlyhp@126.com

Received March 28, 2016 / Accepted August 12, 2016

\begin{abstract}
To explore how Tim-3 is expressed and how its expression influences invasion and metastasis of colorectal cancer (CRC) cells. A total of 188 CRC patients were prospectively collected for this study. Meanwhile, 135 normal controls were incorporated during the same period. Intestinal samples of the $\mathrm{CRC}$ radical cancerous tissues, paracancerous tissues $(<2.0 \mathrm{~cm}$ beyond the cancer tissue) and normal colon mucosa tissues (>5.0 cm beyond the cancer tissue) were collected for the following experiment. Furthermore, peripheral venous blood samples $(10 \mathrm{ml})$ were collected from each subject. Immunohistochemical analysis, quantitative real-time polymerase chain reaction (RT-qPCR) and western blot were performed for the detection of Tim-3 in different tissues. The immunohistochemical staining results showed that a positive Tim-3 signal was localized in the cytoplasm and nucleus, observed as yellow or brown granules. Tim-3 was largely expressed in colon carcinoma tissues and normal colon mucosa tissues but was rarely expressed in the cell membrane. RT-qPCR results indicated that Tim-3 mRNA levels were significantly lower in CRC tissues than in paracancerous tissues and normal colon mucosa tissues. A trend of decreased Tim-3 mRNA levels was also found in the paracancerous tissues compared with the normal colon mucosa tissues (all $P<0.05$ ). Western blot results revealed reduced Tim-3 protein expression in CRC tissues compared with normal colon mucosa tissues and paracancerous tissues, and Tim-3 protein expression was much lower in the paracancerous tissues than in the normal colon mucosa tissues (all $P<0.05$ ). Furthermore, obviously lower Tim-3 mRNA levels were found in the poorly differentiated CRC patients and in those with lymph node metastasis and distant metastasis (all $P<0.05)$. Collectively, Tim-3 expression was mainly located in the cytoplasm and nucleus, showing down-regulated expression in colon carcinoma tissues compared with normal and paracancerous tissues. Reduced Tim-3 expression may promote CRC invasion and metastasis providing a medical reference for the treatment of CRC.
\end{abstract}

Key words: Tim-3, colorectal cancer, protein expression, invasion, metastasis

Colorectal cancer (CRC) originates from the colon or rectum and is capable of invading and migrating to other sites of the body as a result of the abnormal proliferation of tumour cells $[1,2]$. CRC is the second and third most commonly diagnosed cancer in females and males, respectively [3]. Furthermore, CRC is more common in developing countries [4], and a rapid growth in the incidence and mortality of CRC has been observed in China in the past few decades [5, 6]. An estimated one fifth of CRC patients are diagnosed at a far advanced stage, among which over half of the diagnosed cases may develop metastases. Additionally, most of them have unresectable tumours [7], indicating poor prognostic outcomes, with a 5 -year survival rate of below $15 \%$ [8], which may partly be due to the relatively high rates of relapse and metastasis [9]. The risk factors associated with CRC are controversial and complex. The non-genetic risk factors include older age, male gender, unhealthy patterns of diet and lifestyle (high intake of fat, alcohol or red meat, obesity, smoking and a lack of physical exercise), high cholesterol, diabetes, and atherosclerosis [10-13]. Meanwhile, at the cellular level, CRC is a biologically heterogeneous disease that may develop from the progressive accumulation of genetic changes and epigenetic alterations, eventually contributing to cancers from normal colonic epithelium $[14,15]$.

Proteins in the T cell immunoglobulin mucin (Tim) family are type I membrane glycoproteins containing common 
structural motifs, encoding eight members in mice (Tim-1 through Tim-8) and three members in humans (Tim-1, 3, and 4) [16]. The Tim family of cell surface proteins regulates Th1- and Th2-mediated immunity and is implicated in a wide range of autoimmune and allergic-related diseases, cancers, and viral infections [17-19]. Tim-3, initially cloned as a cell surface molecule expressed predominantly by Th1 cells, is the first Tim family member implicated in immune regulation [20]. Tim-3 plays a positive role in innate immune cells, including macrophages/monocytes and natural killer (NK) cells, and can promote the release of inflammatory mediators such as TNF- $\alpha$ and IL-6 [21, 22]. Furthermore, as a specific Th1 cell surface marker, Tim-3 plays an important role as a negative regulator of Th1 and, in turn, stimulates tumour cells escaping immunosurveillance; subsequent studies have documented the inhibitory effect of Tim-3 on Th1-mediated immunity $[23,24]$. The importance of Tim-3 in immune regulation is further underscored by the finding that excessive upregulation of Tim-3 on the mentioned innate immune cells could result in exacerbation of clinical diseases [25-27]. In contrast to the relatively clear mechanisms of Tim-3-mediated T cell activities, it is unknown whether tumour cells or tissues in patients with CRC express Tim-3, and the mechanisms by which Tim-3 is involved in the tumour microenvironment of human CRC also remain largely unclear. Here, in this study, the expression of Tim-3 and how it affected the clinical features of CRC patients was investigated to provide a clinical reference for developing potential useful therapeutic regimens for CRC sufferers.

\section{Patients and methods}

Study subjects. In the present study, all procedures involving human participants were performed in accordance with the ethical standards of the institutional and/or national research committee and with the 1964 Helsinki declaration and its later amendments or comparable ethical standards. All patients (all their caregivers) incorporated in this study were Chinese and were given written informed consent before the study began. During the study accrual, a total of 188 CRC patients were prospectively collected from November 2012 to November 2015 in the local Linyi People's Hospital. There were 98 males and 90 females with a mean age of $58.50 \pm 10.61$ years, ranging from 28 to 72 years old. Intestinal samples were collected from each patient during the same time, including the CRC radical cancerous tissues, paracancerous tissues $(<2.0 \mathrm{~cm}$ beyond the cancer tissue) and normal colon mucosa tissues (> $5.0 \mathrm{~cm}$ beyond the cancer tissue). The inclusion criteria were as follows: (1) All eligible patients were proven to have CRC pathologically with complete clinical data; (2) Patients without a previous history of preoperative radiotherapy and chemotherapy; and (3) The histological pattern for each patient was confirmed according to the Dukes' stage [28] and tumour nodes metastasis (TNM) staging system recommended by the 7th edition of the American Joint Committee on Cancer and Union for International Cancer Control [29]. Meanwhile, there were 135 normal controls that were selected for this study during the same time period at the local hospital for healthy examination (70 males and 65 females ranging from 26 to 76 years, with a mean age of $54.50 \pm 16.26$ ).

Separation of peripheral blood mononuclear cells (PBMCs) and sample processing. Peripheral venous blood samples $(10 \mathrm{ml})$ were drawn from each subject by clean venipuncture. Heparin was the anticoagulant used in this study. PBMC isolation was performed using Ficoll density gradient centrifugation. Then, the collected samples were inoculated in the culture dish and placed at $37^{\circ} \mathrm{C}$ and $50 \mathrm{ml} / \mathrm{L} \mathrm{CO}_{2}$ in a culture box for $2 \mathrm{~h}$. Subsequently, the supernatant was discarded, and the adherent cells (monocytes) were collected for further use. The mononuclear cell purity was greater than or equal to $80 \%$ using the density gradient centrifugation and adherence method.

In addition, all blood and tissue specimens were quickly placed in liquid nitrogen and maintained at $-80^{\circ} \mathrm{C}$ for $10 \mathrm{~min}$. Half of the cancerous tissues were fixed with $10 \%$ formalin and embedded in paraffin for immunohistochemical analysis. From each paraffin block, $4-\mu \mathrm{m}$ thick serial sections were prepared and roasted in an oven at a constant temperature of $60^{\circ} \mathrm{C}$ for $1 \mathrm{~h}$. In addition, the remaining cancerous specimens, their corresponding paracancerous specimens and normal tissues were prepared for extraction of RNA and protein for further quantitative real-time polymerase chain reaction (RT-qPCR) and western blot detection.

Immunohistochemical detection. All sections were subjected to conventional dewaxing and were repaired under controlled high temperature and high pressure conditions in strict accordance with the kit protocol. The primary antibody concentration was pre-set at 1:100. The blank control had PBS in place of the primary antibody, and known positive sections were used as positive controls. First, staining intensity was scored as: (1) 0 points, no intensity staining; (2) 1 point, low intensity (light yellow); (3) 2 points, moderate intensity (yellow brown); and (4) 3 points, high intensity (dark brown). Then, the corresponding scoring results were valued in terms of the proportion of positive cells: 0 points, negative cells; 1 point, positive cells less than or equal to $10 \%$; 2 points, positive cells $11 \%-50 \%$; 3 points, positive cells 51\%-75\%; and 4 points, positive cells $>75 \%$. The immunohistochemical staining results were evaluated by two experienced pathologists under double-blind conditions.

RT-qPCR detection. RNA extraction from blood and tissue samples was carried out using the Trizol kit according to the manufacturer's protocol. A total of $1 \mathrm{ml}$ of extracted total RNA was added to $1 \times 10^{6}$ cells, and the final RNA products were stored at $-80^{\circ} \mathrm{C}$. Furthermore, cDNA synthesis was performed by RT-PCR (QIAGEN) and followed by preservation at $-20^{\circ} \mathrm{C}$. According to the sequence of human $\beta$-actin (GI: 168480144) and Tim-3 (GI: 354681988) in NCBI Gen Bank, Premier Primer 5.0 software (Premier Biosoft International, Palo Alto, CA, USA) was used for the 
design of specific primers. Meanwhile, PCR thermal cycle parameters were: $95^{\circ} \mathrm{C}$ for $4 \mathrm{~min}$, followed by 40 cycles of $95^{\circ} \mathrm{C}$ for $30 \mathrm{~s}, 60^{\circ} \mathrm{C}$ for $30 \mathrm{~s}$ and $72{ }^{\circ} \mathrm{C}$ for $30 \mathrm{~s}$. The final fluorescence of these reactions was plotted at the last step of each cycle. The melting curve was repeated for 2 cycles at $95^{\circ} \mathrm{C}$ for $2 \mathrm{~min}, 95^{\circ} \mathrm{C}$ for $15 \mathrm{~s}$ and $60^{\circ} \mathrm{C}$ for $1 \mathrm{~min}$. The relative mRNA expression levels of Tim- 3 and $\beta$-actin were further determined by $2^{-\Delta \Delta C}$ t. The CT value was predefined as the amplification power curve inflection point [30]. The capture probe sequences for Tim-3 are shown in Supplementary Table 1.

Western blot analyses. Total protein from the cancerous tissues and adjacent paracancerous and normal tissues were extracted in RIPA lysis buffer, in accordance with the kit protocol using the rapid Bicinchoninic acid (BCA) method for quantification of total protein. A total of $50 \mu \mathrm{g}$ of proteins was subjected to $10 \%$ SDS-PAGE and transferred to a PVDF membrane. The membrane was blocked with $5 \%$ skim milk, rabbit anti-human AGR2 polyclonal antibody (diluted at 1:1000) and rabbit anti-human $\beta$-actin polyclonal antibody (diluted at 1:200) were added to the membrane, and the membrane was incubated overnight at $4{ }^{\circ} \mathrm{C}$. After briefly washing the membrane three times with TBST buffer, HRP-labelled Goat anti-rabbit secondary antibody was added, and then the membrane was incubated at room temperature for $1 \mathrm{~h}$. All antibodies used in this experiment were purchased from Abcam Inc., Cambridge, MA, USA. Following another wash with TBST, positive bands were revealed by autoradiography after the addition of a chemiluminescence reagent. Levels relative to grey protein and $\beta$-actin ratio were determined by semi-quantitative analysis. Quantification was performed by estimating the grey value ratios of the target protein and the reference $\beta$-actin.

Statistical analysis. SPSS version 19.0 statistical software (SPSS Inc., Chicago, IL, USA) was used to analyse the inputted data files. Enumeration data and measurement data were expressed as rates or percentages and as mean \pm standard deviation (SD), respectively, and the corresponding comparison tests were the chi-square test and $t$-test, respectively. All the tests in this study were two-sided. A $P$ value $<0.05$ was considered statistically significant.

\section{Results}

Baseline characteristics of included subjects. In this study, as presented in Table 1, there were 98 males and 90 females in the case group, with a mean age of $58.50 \pm 10.61$ years. Additionally, there were 135 normal controls, consisting of 70 males and 65 females, with a mean age of $54.50 \pm 16.26$. No evident statistical significance was detected regarding gender and age distributions between the groups (both $P>0.05$ ), which were comparable. In the case group, histological grades were: well-differentiated $(n=60)$, moderately differentiated $(\mathrm{n}=77)$ and poorly differentiated $(\mathrm{n}=51)$. Regarding TNM stages, 28 patients were in stage I, 45 in stage II, 62 in stage
III and 53 in stage IV. In addition, there were 90 patients who had lymphatic metastasis, 98 patients with no lymphatic metastasis, and 44 patients with distant metastasis. Additionally, with respect to the clinical stage, there were 43 in stage I, 22 in stage II, 87 in stage III and 36 in stage IV.

Immunohistochemical results. As shown in Figure 1, immunohistochemical staining revealed that the Tim-3 protein was localized mainly in the cytoplasm and nucleus, showing yellow or brown granules. In addition, Tim-3 was found to be largely expressed in colon carcinoma tissues and normal colon mucosa tissues but was rarely expressed in the cell membrane.

Tim-3 mRNA and protein expression levels in CRC specimens and in PBMCs. The relative mRNA expression of Tim-3 was quantified in monocytes from the peripheral blood and tissues of patients by the $2^{-\Delta \Delta C} t$ method. There was a positive decreased trend of Tim-3 mRNA levels in monocytes from the peripheral blood of CRC patients compared with normal controls $(P<0.05)$. Compared with paracancerous tissues and normal colon mucosa tissues, Tim-3 mRNA levels were significantly lowered in CRC tissues (both $P<0.05$ ). Furthermore, even lower mRNA levels of Tim- 3 were detected

Table 1. Relationship between Tim-3 mRNA expression levels and the clinicopathologic parameters of 188 patients with colorectal cancer

\begin{tabular}{|c|c|c|c|}
\hline \multirow{2}{*}{ Variables } & \multicolumn{3}{|c|}{ Tim-3 mRNA levels } \\
\hline & Low levels & High levels & $P$ \\
\hline \multicolumn{4}{|l|}{ Gender } \\
\hline Male & 57 & 41 & \multirow{2}{*}{0.571} \\
\hline Female & 56 & 34 & \\
\hline \multicolumn{4}{|l|}{ Age } \\
\hline$<60$ & 48 & 40 & \multirow{2}{*}{0.145} \\
\hline$\geq 60$ & 65 & 35 & \\
\hline \multicolumn{4}{|l|}{ Differentiation } \\
\hline Well & 42 & 18 & \multirow{3}{*}{0.018} \\
\hline Moderately & 37 & 40 & \\
\hline Poorly & 34 & 17 & \\
\hline \multicolumn{4}{|l|}{ TNM stages } \\
\hline I & 18 & 10 & \multirow{4}{*}{0.583} \\
\hline II & 26 & 19 & \\
\hline III & 38 & 24 & \\
\hline IV & 31 & 22 & \\
\hline \multicolumn{4}{|c|}{ Lymph node metastasis } \\
\hline With & 70 & 20 & \multirow{2}{*}{$<0.001$} \\
\hline Without & 43 & 55 & \\
\hline \multicolumn{4}{|c|}{ Distant metastasis } \\
\hline With & 33 & 11 & \multirow{2}{*}{0.022} \\
\hline Without & 80 & 64 & \\
\hline \multicolumn{4}{|l|}{ Clinical stages } \\
\hline I & 18 & 21 & \multirow{4}{*}{0.054} \\
\hline II & 10 & 12 & \\
\hline III & 59 & 28 & \\
\hline IV & 26 & 14 & \\
\hline
\end{tabular}




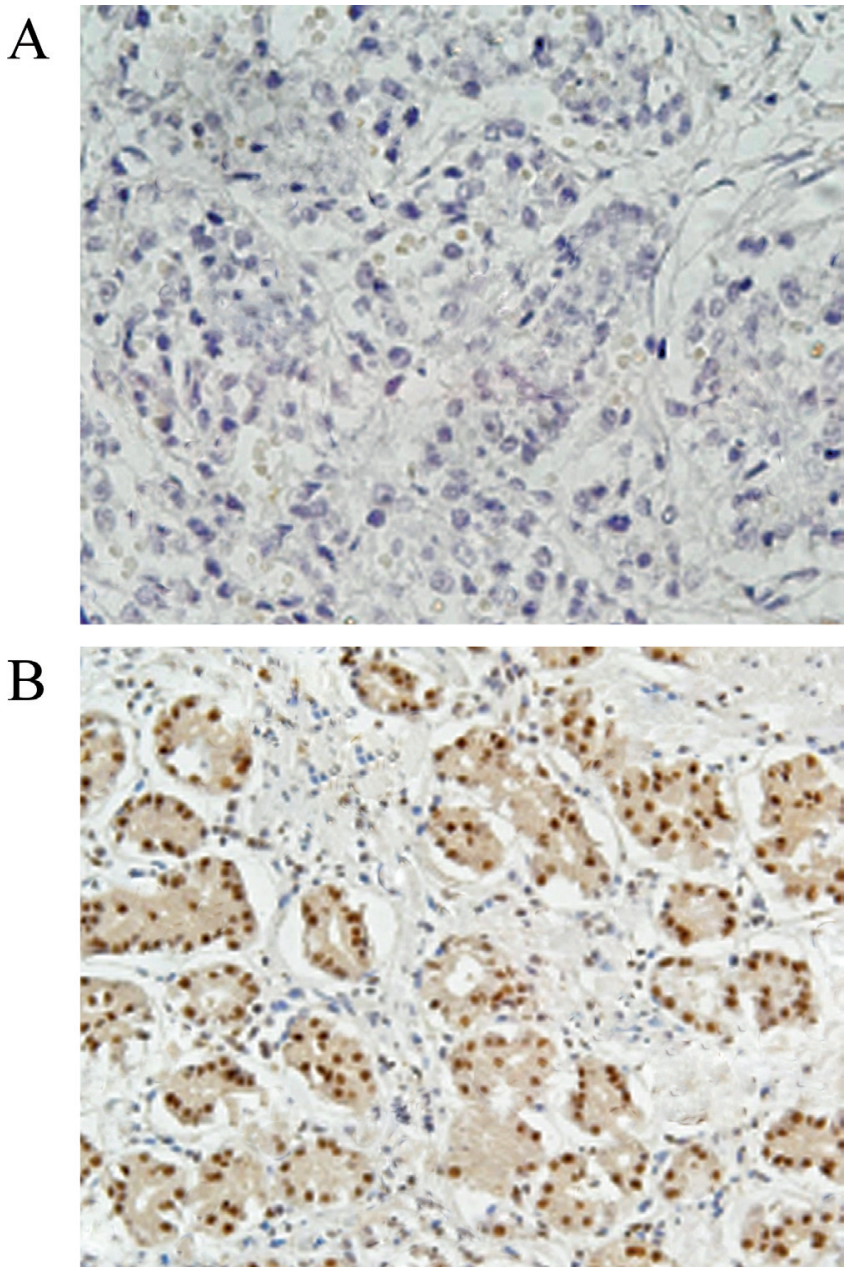

Figure 1. Immunohistochemical staining results of the positive signals of Tim-3 protein and its expression. Tim-3 was localized in the cytoplasm and nucleus, showing yellow or brown granules. Tim-3 was largely expressed in colon carcinoma tissues and normal colon mucosa tissues, and it was rarely expressed in the cell membrane ( $A$, in colon carcinoma tissues; $B$, in normal colon mucosa tissues).

in the paracancerous tissues than in the normal colon mucosa tissues (Figure 2).

Furthermore, to observe the protein expression levels of Tim-3 in CRC, further verification of the protein expression of Tim-3 in human tissues was performed by western blot. The corresponding results showed that reduced expression of Tim-3 protein in CRC tissues was detected compared with normal colon mucosa tissues and paracancerous tissues; the differences were statistically significant (both $P<0.05$ ). A similar result was also found in the comparison of Tim-3 protein expression between the paracancerous tissues and the normal colon mucosa tissues; of the two, the former had a lower expression level than the latter $(P<0.05)$ (Figure 3$)$.

Relationships between Tim-3 mRNA levels and the clinicopathologic parameters of CRC. Gender, age, differ-
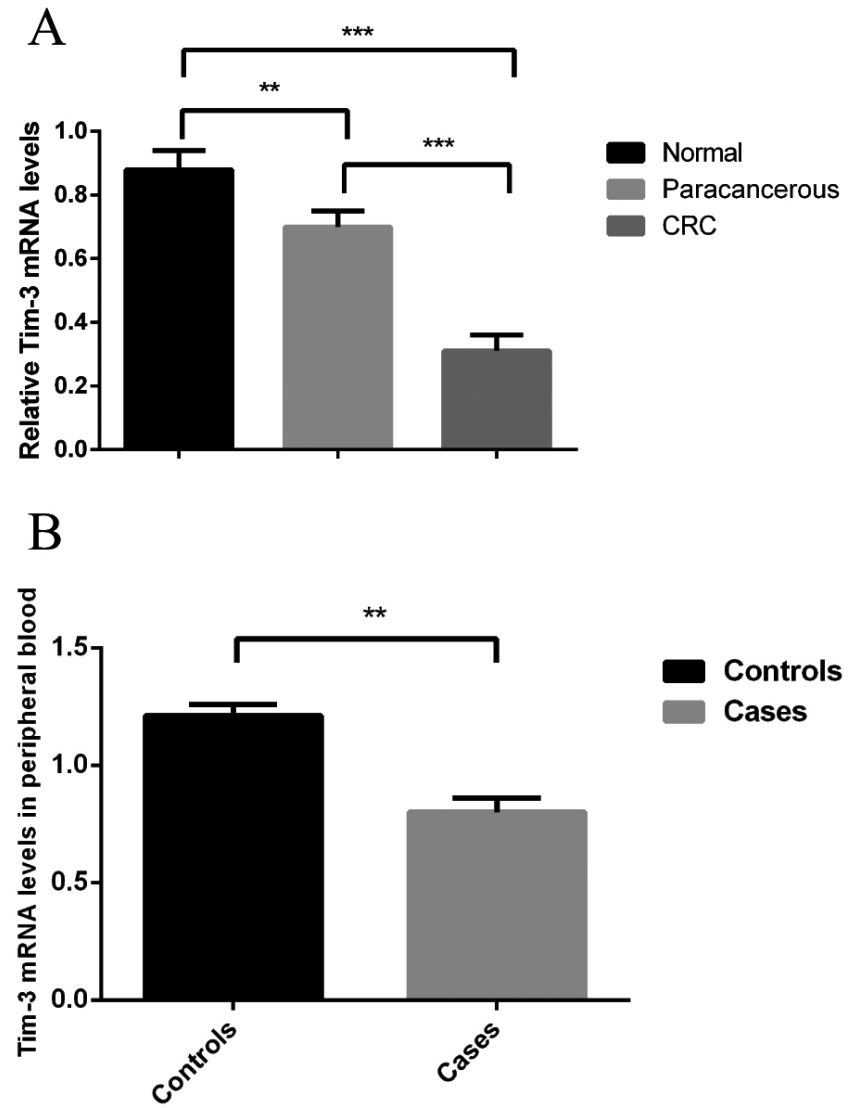

Figure 2. The mRNA levels of Tim-3 measured by RT-PCR. A, The relative mRNA expression levels of Tim- 3 in human tissues were quantified using the $2^{-\Delta \Delta C}$ t method. Compared with paracancerous tissues and normal colon mucosa tissues, the levels of Tim-3 mRNA were significantly lower in CRC tissues; a decreased tendency was further found in the paracancerous tissues compared with the normal colon mucosa tissues; B, There was a positive decreased trend of Tim-3 mRNA levels in monocytes from the peripheral blood of CRC patients. ${ }^{* *}$, compared with normal colon mucosa tissues, $P<0.05$; ${ }^{* *}$, compared with the paracancerous tissues and the normal colon mucosa tissues. RT-qPCR, quantitative real-time polymerase chain reaction; $\mathrm{CRC}$, colorectal cancer.

entiation degree, TNM stages, lymph node metastasis, distant metastasis and clinical stages were investigated in this experiment to confirm the relationship of Tim-3 mRNA levels with the clinicopathologic parameters of CRC (Table 1). In total, there were 113 cases with low expression of Tim-3, and the remaining 75 cases had high expression of Tim-3. The results indicated that there were statistically significant associations between Tim-3 mRNA levels and differentiation degree, lymph node metastasis and distant metastasis, where obviously lower Tim-3 mRNA levels were found in the poorly differentiated CRC patients and in those with lymph node metastasis and with distant metastasis (all $P<0.05$ ). However, regarding other parameters including gender, age, TNM stages and clinical stages, no apparent statistical differences were found (all $P>0.05$ ). 


\section{Discussion}

The Tim gene family, which is mainly expressed on the surface of immune cells, has potential influence in tumour immune surveillance and immune escape $[23,31]$. Importantly and cautiously, different microenvironments of tumours may affect Tim targeting treatment response to different therapy regimens. The Tim-3 protein, which is considered to be an important member of the Tim family mainly expressed on the surface of activated Thl cells, plays critical roles in regulating immune function after binding with its ligands, which may be regarded as new targets for the treatment of human cancers [32-34]. In this study, the expression of Tim-3 in CRC patients was investigated to explore the relationship of Tim-3 expression with the clinicopathologic parameters of CRC.

According to our study, the immunohistochemical results showed that the Tim-3 protein was mainly expressed in the cytoplasm and nucleus of normal gastric mucosa and gastric carcinoma tissues, and it was rarely expressed in the cell membrane. Furthermore, samples were collected from 188 cases of CRC radical patients' cancerous tissues, paracancerous tissues and normal colon mucosa tissues; all cases were confirmed CRC by pathology. Tim-3 mRNA levels were detected by RT-qPCR. The results showed that Tim-3 mRNA levels in cancerous tissues were significantly lower than those in paracancerous tissues and normal colon mucosa tissues. At the same time, Tim-3 protein expression of the incorporated tissues was detected by western blot, and the results were in agreement with the detection results of Tim-3 mRNA levels. Those results suggested that low expression of Tim-3 might be strongly correlated with the progression and development of CRC. Additionally, a positive decreased trend of Tim-3 mRNA levels was also observed in monocytes from the peripheral blood of CRC patients. Therefore, we would hypothesize that the detection of Tim-3 expression in both the peripheral blood samples and human tissues can be used as potential anti-tumour treatment indicators, which would require future in-depth experimental study. The possible mechanism associated with the above speculation might be that Tim-3 expressed on tumour cells and tumour-associated immune cells has diverse tumourigenic activities contributing to tumour-initiating and tumour-promoting activities [35-37]. With regard to this, the inhibition of Tim-3 expression with certain antagonists or by interference in relevant signal pathways may be useful for the suppression of Tim-3 expression, thereby leading to tumour suppression. Accumulating evidence has revealed that Tim-3 has pleiotropic functions affecting multiple immunologic and biologic properties of various types of cells, such as galectin-9 and high-mobility group box 1 [38-40]. Correspondingly, Tim-3 expression was detected on a large number of tumours, and lower Tim-3 expression was positively correlated with shorter progression-free survival in patients with clear cell renal cell carcinoma [36]. It is therefore important that treatment with anti-Tim-3 may suppress

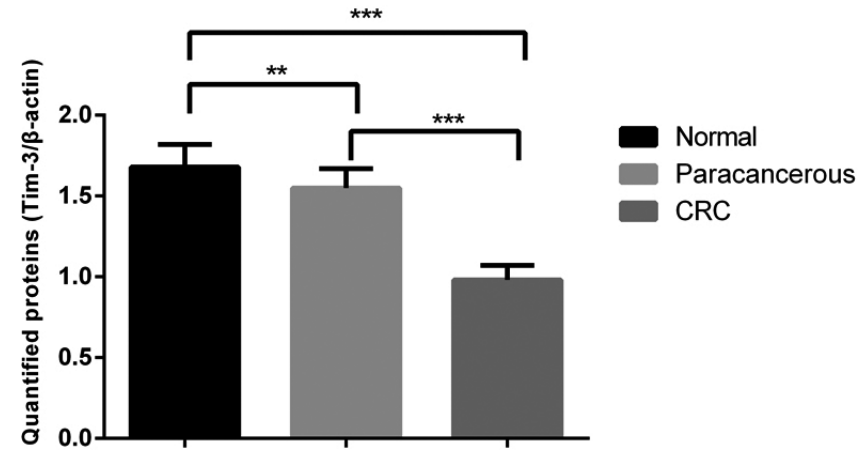

Figure 3. Tim-3 protein expression measured by western blot. Reduced expression of the Tim-3 protein was observed in CRC tissues compared with normal colon mucosa tissues and paracancerous tissues; of the two, the former had a lower expression level than the latter. ${ }^{* *}$ compared with normal colon mucosa tissues, $P<0.05$; ${ }^{* * *}$ compared with the paracancerous tissues and the normal colon mucosa tissues. CRC, colorectal cancer.

its tumourigenic effects, which needs to be further confirmed in in vitro and in vivo settings.

A number of studies have indicated that down-regulation of Tim-3 expression in tumours may promote tumour progression and metastasis. To this end, we analysed the association of Tim-3 mRNA levels with the clinical parameters of CRC. Differentiation degree, lymph node metastasis and distant metastasis were clearly significant. However, no significant difference was found with respect to the expression of Tim-3 with different gender, age, TNM stages and clinical stages, which should be interpreted cautiously due to the restricted inclusion of samples and different backgrounds such as lifestyle and family history. Generally, poorer differentiation grade, higher TNM stages and metastasis status as well as serious clinical stage were recognized as the risk factors for $\mathrm{CRC}$ cell invasion and metastasis, and the association between those indicators and CRC highlighted the important role of Tim-3 in predicting invasion and metastasis of CRC. Based on the above results, the expression of Tim-3 in CRC tissue was significantly decreased, and there was a certain correlation with the clinical and pathological stage of this cancer. In view of previous investigations, Gao X et al. showed that Tim-3 was highly expressed in human lung cancer tissues, and their study also revealed a close correlation of Tim-3 expression with nodal metastasis and advanced cancer stages of nonsmall cell lung cancer, possibly due to the role of Tim-3 as an important immune regulator via its predominant expression in regulatory $\mathrm{T}$ cells in the tumour microenvironment [41]. On the other hand, via a blockade of Tim-3, the proliferation and invasion of cancer cells could be significantly inhibited; for example, Tim-3 blockade could reverse tumour-induced $\mathrm{T}$ cell dysfunction significantly in patients with advanced melanoma [27].

Taken as a whole, our study revealed that Tim-3 was mainly located in the cytoplasm and nucleus, and decreased mRNA and protein expression were found in CRC patients' blood 
and tissue samples. Reduced Tim-3 expression might promote CRC invasion and metastasis, which provided a reference for developing treatment strategies for CRC patients and clinicians. Our study had several limitations. First, we only investigated the correlation between the expression of Tim-3 and CRC, and the mechanism of how decreased Tim-3 expression promotes CRC cell invasion and metastasis needs to be further studied. The small sample size of the present study was also a limitation which might lead to low power. However, clearly this study put forward the idea that suppressing Tim-3 expression may play an efficient role against cancer in the application of relevant antagonists or in the intervention of relevant signal pathways.

Supplementary information is available in the online version of the paper.

\section{References}

[1] LAM CS, CHEUNG AH, WONG SK, WAN TM, NG L et al. Prognostic significance of CD26 in patients with colorectal cancer. PLoS One 2014; 9: e98582. https:/doi.org/10.1371/ journal.pone.0098582

[2] SIEGEL R, DESANTIS C, JEMAL A. Colorectal cancer statistics, 2014. CA Cancer J Clin 2014; 64: 104-117. https:/doi. org/10.3322/caac. 21220

[3] JEMAL A, BRAY F, CENTER MM, FERLAY J, WARD E et al. Global cancer statistics. CA Cancer J Clin 2011; 61: 69-90. https:/doi.org/10.3322/caac.20107

[4] ZARATE AJ, ALONSO FT, GARMENDIA ML, LOPEZKOSTNER F. Increasing crude and adjusted mortality rates for colorectal cancer in a developing South American country. Colorectal Dis 2013; 15: 47-51. https:/doi.org/10.1111/j.14631318.2012.03110.x

[5] SUN K, DENG HJ, LEI ST, DONG JQ, LI GX. miRNA-338 $-3 p$ suppresses cell growth of human colorectal carcinoma by targeting smoothened. World J Gastroenterol 2013; 19: 2197-2207. https:/doi.org/10.3748/wig.v19.i14.2197

[6] SUN K, WANG W, ZENG JJ, WU CT, LEI ST et al. MicroRNA221 inhibits CDKN1C/p57 expression in human colorectal carcinoma. Acta Pharmacol Sin 2011; 32: 375-384. https:/ doi.org/10.1038/aps.2010.206

[7] VAN CUTSEM E, NORDLINGER B, CERVANTES A, GROUP EGW. Advanced colorectal cancer: ESMO Clinical Practice Guidelines for treatment. Ann Oncol 2010; 21 Suppl 5: v93-97. https:/doi.org/10.1093/annonc/mdq222

[8] NEDREBO BS, SOREIDE K, ERIKSEN MT, KVALOY JT, SOREIDE JA et al. Excess mortality after curative surgery for colorectal cancer changes over time and differs for patients with colon versus rectal cancer. Acta Oncol 2013; 52: 933-940. https:/doi.org/10.3109/0284186X.2012.731522

[9] TAKII Y, SHIMADA Y, MORIYA Y, NAKAMURA K, KATAYA$\mathrm{MA} \mathrm{H}$ et al. A randomized controlled trial of the conventional technique versus the no-touch isolation technique for primary tumor resection in patients with colorectal cancer: Japan Clinical Oncology Group Study JCOG1006. Jpn J Clin Oncol 2014; 44: 97-100. https:/doi.org/10.1093/jico/hyt156
[10] MURDOCCA M, MANGO R, PUCCI S, BIOCCA S, TESTA $B$ et al. The lectin-like oxidized LDL receptor-1: a new potential molecular target in colorectal cancer. Oncotarget 2016; 7 : 14765-14780.

[11] DE BRUIJN KM, ARENDS LR, HANSEN BE, LEEFLANG $\mathrm{S}$, RUITER R et al. Systematic review and meta-analysis of the association between diabetes mellitus and incidence and mortality in breast and colorectal cancer. Br J Surg 2013; 100: 1421-1429. https:/doi.org/10.1002/bjs.9229

[12] KYRO C, SKEIE G, LOFT S, OVERVAD K, CHRISTENSEN $\mathrm{J}$ et al. Adherence to a healthy Nordic food index is associated with a lower incidence of colorectal cancer in women: the Diet, Cancer and Health cohort study. Br J Nutr 2013; 109: 920-927. https:/doi.org/10.1017/S0007114512002085

[13] WATSON AJ, COLLINS PD. Colon cancer: a civilization disorder. Dig Dis 2011; 29: 222-228. https:/doi. org/10.1159/000323926

[14] WU R, SU Y, WU H, DAI Y, ZHAO M et al. Characters, functions and clinical perspectives of long non-coding RNAs. Mol Genet Genomics 2016; 291: 1013-1033. https:/doi. org/10.1007/s00438-016-1179-y

[15] CHANG SC, LIN PC, LIN JK, LIN CH, YANG SH et al. Mutation Spectra of Common Cancer-Associated Genes in Different Phenotypes of Colorectal Carcinoma Without Distant Metastasis. Ann Surg Oncol 2016; 23: 849-855. https:/ doi.org/10.1245/s10434-015-4899-Z

[16] JI H, LIU Y, ZHANG Y, SHEN XD, GAO F et al. T-cell immunoglobulin and mucin domain 4 (TIM-4) signaling in innate immune-mediated liver ischemia-reperfusion injury. Hepatology 2014; 60: 2052-2064. https:/doi.org/10.1002/hep.27334

[17] XIAO S, BROOKS CR, ZHU C, WU C, SWEERE JM et al. Defect in regulatory B-cell function and development of systemic autoimmunity in T-cell Ig mucin 1 (Tim-1) mucin domain-mutant mice. Proc Natl Acad Sci U S A 2012; 109: 12105-12110. https:/doi.org/10.1073/pnas.1120914109

[18] SAKUISHI K, APETOH L, SULLIVAN JM, BLAZAR BR, KUCHROO VK et al. Targeting Tim-3 and PD-1 pathways to reverse T cell exhaustion and restore anti-tumor immunity. J Exp Med 2010; 207: 2187-2194. https:/doi.org/10.1084/ jem.20100643

[19] JU Y, HOU N, MENG J, WANG X, ZHANG X et al. T cell immunoglobulin- and mucin-domain-containing molecule-3 (Tim-3) mediates natural killer cell suppression in chronic hepatitis B. J Hepatol 2010; 52: 322-329. https:/doi. org/10.1016/j.jhep.2009.12.005

[20] ZHANG Y, MA CJ, WANG JM, JI XJ, WU XY et al. Tim-3 regulates pro- and anti-inflammatory cytokine expression in human CD14+ monocytes. J Leukoc Biol 2012; 91: 189-196. https:/doi.org/10.1189/jlb.1010591

[21] HAN G, CHEN G, SHEN B, LI Y. Tim-3: an activation marker and activation limiter of innate immune cells. Front Immunol 2013; 4: 449. https:/doi.org/10.3389/fimmu.2013.00449

[22] UCHIDA Y, KE B, FREITAS MC, YAGITA H, AKIBA H et al. T-cell immunoglobulin mucin-3 determines severity of liver ischemia/reperfusion injury in mice in a TLR4-dependent manner. Gastroenterology 2010; 139: 2195-2206. https:/doi. org/10.1053/j.gastro.2010.07.003 
[23] ZHU C, ANDERSON AC, KUCHROO VK. TIM-3 and its regulatory role in immune responses. Curr Top Microbiol Immunol 2011; 350: 1-15. https:/doi. org/10.1007/82 2010 84

[24] DARDALHON V, ANDERSON AC, KARMAN J, APETOH L, CHANDWASKAR R et al. Tim-3/galectin-9 pathway: regulation of Th1 immunity through promotion of CD11b+Ly-6G+ myeloid cells. J Immunol 2010; 185: 1383-1392. https:/doi.org/10.4049/jimmunol.0903275

[25] NEBBIA G, PEPPA D, SCHURICH A, KHANNA P, SINGH HD et al. Upregulation of the Tim-3/galectin-9 pathway of $\mathrm{T}$ cell exhaustion in chronic hepatitis $\mathrm{B}$ virus infection. PLoS One 2012; 7: e47648. https:/doi.org/10.1371/journal. pone. 0047648

[26] ZHOU Q, MUNGER ME, VEENSTRA RG, WEIGEL BJ, HIRASHIMA $\mathrm{M}$ et al. Coexpression of Tim-3 and PD-1 identifies a CD8+ T-cell exhaustion phenotype in mice with disseminated acute myelogenous leukemia. Blood 2011; 117: 4501-4510. https:/doi.org/10.1182/blood-2010-10-310425

[27] FOURCADE J, SUN Z, BENALLAOUA M, GUILLAUME P, LUESCHER IF et al. Upregulation of Tim-3 and PD-1 expression is associated with tumor antigen-specific CD8+ T cell dysfunction in melanoma patients. J Exp Med 2010; 207: 2175-2186. https:/doi.org/10.1084/jem.20100637

[28] GREENE FL, SOBIN LH. A worldwide approach to the TNM staging system: collaborative efforts of the AJCC and UICC. J Surg Oncol 2009; 99: 269-272. https:/doi.org/10.1002/ jso. 21237

[29] AKKOCA AN, YANIK S, OZDEMIR ZT, CIHAN FG, SAYAR $S$ et al. TNM and Modified Dukes staging along with the demographic characteristics of patients with colorectal carcinoma. Int J Clin Exp Med 2014; 7: 2828-2835.

[30] KRISHNADAS R, CAVANAGH J. Depression: an inflammatory illness? J Neurol Neurosurg Psychiatry 2012; 83: 495-502. https:/doi.org/10.1136/jnnp-2011-301779

[31] HUANG X, BAI X, CAO Y, WU J, HUANG M et al. Lymphoma endothelium preferentially expresses Tim-3 and facilitates the progression of lymphoma by mediating immune evasion. J Exp Med 2010; 207: 505-520. https:/doi. org/10.1084/jem.20090397

[32] WANG L, ZHAO C, PENG Q, SHI J, GU G. Expression levels of CD28, CTLA-4, PD-1 and Tim-3 as novel indicators of
T-cell immune function in patients with chronic hepatitis $\mathrm{B}$ virus infection. Biomed Rep 2014; 2: 270-274.

[33] CHABTINI L, MFARREJ B, MOUNAYAR M, ZHU B, BATAL I et al. TIM-3 regulates innate immune cells to induce fetomaternal tolerance. J Immunol 2013; 190: 88-96. https:/doi. org/10.4049/jimmunol.1202176

[34] ANDERSON AC. Tim-3, a negative regulator of anti-tumor immunity. Curr Opin Immunol 2012; 24: 213-216. https:/doi. org/10.1016/j.coi.2011.12.005

[35] KANG CW, DUTTA A, CHANG LY, MAHALINGAM J, LIN YC et al. Apoptosis of tumor infiltrating effector TIM-3+CD8+ T cells in colon cancer. Sci Rep 2015; 5: 15659. https:/doi. org/10.1038/srep15659

[36] KOMOHARA Y, MORITA T, ANNAN DA, HORLAD H, OHNISHI $\mathrm{K}$ et al. The Coordinated Actions of TIM-3 on Cancer and Myeloid Cells in the Regulation of Tumorigenicity and Clinical Prognosis in Clear Cell Renal Cell Carcinomas. Cancer Immunol Res 2015; 3: 999-1007. https:/doi. org/10.1158/2326-6066.CIR-14-0156

[37] RAMELLO MC, TOSELLO BOARI J, CANALE FP, MENA HA, NEGROTTO $S$ et al. Tumor-induced senescent T cells promote the secretion of pro-inflammatory cytokines and angiogenic factors by human monocytes/macrophages through a mechanism that involves Tim-3 and CD40L. Cell Death Dis 2014; 5: e1507.

[38] GAO L, YU S, ZHANG X. Hypothesis: Tim-3/galectin-9, a new pathway for leukemia stem cells survival by promoting expansion of myeloid-derived suppressor cells and differentiating into tumor-associated macrophages. Cell Biochem Biophys 2014; 70: 273-277. https:/doi.org/10.1007/s12013-014-9900-0

[39] TANG D, LOTZE MT. Tumor immunity times out: TIM-3 and HMGB1. Nat Immunol 2012; 13: 808-810. https:/doi. org/10.1038/ni.2396

[40] CHIBA S, BAGHDADI M, AKIBA H, YOSHIYAMA H, KINOSHITA I et al. Tumor-infiltrating DCs suppress nucleic acid-mediated innate immune responses through interactions between the receptor TIM-3 and the alarmin HMGB1. Nat Immunol 2012; 13: 832-842. https:/doi.org/10.1038/ni.2376

[41] GAO X, ZHU Y, LI G, HUANG H, ZHANG G et al. TIM-3 expression characterizes regulatory $\mathrm{T}$ cells in tumor tissues and is associated with lung cancer progression. PLoS One 2012; 7 : e30676. https:/doi.org/10.1371/journal.pone.0030676 
Supplementary Table 1 Capture probe sequences for Tim-3 gene

\begin{tabular}{ll}
\hline & Primers \\
\hline Tim-3 & F: 5'-CCAAATCCCAGGCATAAT-3' \\
& R: 5'-AAGCGA-CAACCCAAAGGT-3' \\
$\beta$-actin & F: 5'-CGAAACTACCT-TCAACTCCATC-3' \\
& R: 5'-AGTGATCTCCTTCTGCATCCT-3' \\
\hline
\end{tabular}

Note: F, forward; R, reverse. 